\title{
Estabilidade dos carotenóides e propriedades físico-químicas da oleoresina de páprica microencapsulada por spray drying
}

\section{Eveling O. Bezerra*, Ana G. S. Anthero, Fernanda R. Procópio, Talita A. Comunian, Miriam D. Hubinger}

\section{Resumo}

O objetivo do trabalho foi microencapsular a oleoresina de páprica(OP) por spray drying utilizando goma arábica (GA) e amidos modificados EMCAP (amido de milho esterificado com octenil succínico) e snow-flake (SN) (amido de milho ceroso pré-gelatinizado) como materiais encapsulantes. Foram obtidas partículas de OP solúveis em água, sendo que as formulações com GA e SN promoveram maior estabilidade aos carotenóides e à cor, tornando esses produtos potenciais ingredientes para uso em alimentos.

\section{Palavras-chave:}

Emulsão, pimentão vermelho, amido modificado e goma arábica.

\section{Introdução}

A OP obtida do pimentão vermelho é extraída por solvente orgânico, e apresenta em sua composição ácidos graxos, triglicerídeos, e carotenoides como a capsaxantina, capsorubina, zeaxantina, $\beta$ - criptoxantina e $\beta$-caroteno. Devido à baixa solubilidade em água e instabilidade desses compostos frente às adversidades de processamento, como alta temperatura, a encapsulação do composto é uma alternativa para ampliar o uso da oleoresina de páprica em alimentos. Diante disso, esta pesquisa teve como objetivo estudar a influência dos diferentes materiais encapsulantes (GA, SN e EMCAP) e a combinação dos mesmos, sobre a estabilidade dos carotenoides e propriedades físicoquímicas, nas micropartículas de OP produzidas por emulsões óleo em água seguidas pela atomização por spray drying.

\section{Resultados e Discussão}

Emulsões contendo $20 \%(\mathrm{~m} / \mathrm{m})$ de materiais de parede GA, EMCAP e SN, com 2,5\% $(\mathrm{m} / \mathrm{m})$ de OP em relação à concentração de encapsulante, foram preparadas em um rotor-estator (Silverson; L5M-A) a $5.000 \mathrm{rpm}$ por $10 \mathrm{~min}$. Todas as emulsões foram caracterizadas e submetidas à secagem por spray dryer com pressão de ar do compressor de 0,06 MPa, vazão de alimentação de 30 $(\mathrm{mL} / \mathrm{min})$, e temperaturas de entrada e saída de 160 e $90^{\circ} \mathrm{C}$, respectivamente. As micropartículas foram analisadas em relação à umidade, atividade de água (aw), morfologia por microscopia eletrônica de varredura, eficiência de encapsulação, retenção de carotenoides $e$ cor durante 45 dias de estocagem à 25 e $35^{\circ} \mathrm{C}$. As emulsões apresentaram baixo índice de instabilidade, inferior à $9 \%$ após $24 \mathrm{~h}$ ao preparo, sendo que as compostas por um único material encapsulante apresentaram melhores resultados. As micropartículas obtidas por spray dryer apresentaram forma esférica, independentemente do material de parede utilizado (Fig.1), e diâmetro $D_{43}$ variando de 9,2 a $31,3 \mu \mathrm{m}$. A aw e umidade se mantiveram baixas, o que contribui na estabilidade contra o crescimento de microrganismos e reações bioquímicas na estocagem. Em relação à higroscopicidade, verificou-se que as micropartículas utilizando GA como material de parede apresentaram maiores valores $(11,3 \pm 0,5$ a $13,6 \pm 0,7 \%)$. Todas as micropartículas apresentaram alto índice de solubilidade (>90\%), tornando possível o uso dos mesmos em uma matriz alimentícia a base de água. As micropartículas também apresentaram alta eficiência de encapsulação em relação ao óleo total presente na partícula (variando de 89,7 a 95,3\%) e consequentemente alta retenção de carotenoides e cor alaranjada característica da OP. Ao longo do estudo de estabilidade, observou-se a perda significativa de carotenoides e cor na maioria dos pós a partir de 15 e 30 dias à 35 e $25^{\circ} \mathrm{C}$ respectivamente (Fig.1). Os pós contendo $\mathrm{SN}$ apresentaram maiores retenções de carotenoides ao longo do tempo, em relação às demais amostras e à OP pura (controle), enquanto os contendo EMCAP, as menores. Concomitantemente, ocorreu perda de cor das amostras com a redução do teor dos carotenoides (mg de carotenóides/ g de micropartículas) revelando a influência do material encapsulante sobre a preservação do composto encapsulado.
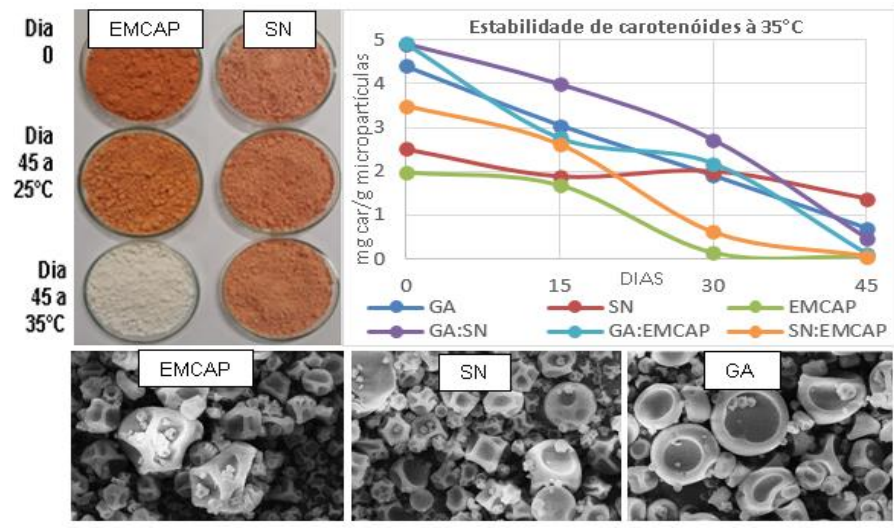

Figura 1. Estabilidade de cor e carotenoides ao longo do tempo, e microscopia eletrônica de varredura.

\section{Conclusões}

Todas as formulações apresentaram alto teor de carotenoides, alta solubilidade e baixa atividade de água, e podem ser aplicados em alimentos como fonte de cor e compostos bioativos, sendo que as mais estáveis ao armazenamento foram as compostas pelos biopolímeros $\mathrm{SN}$ e GA.

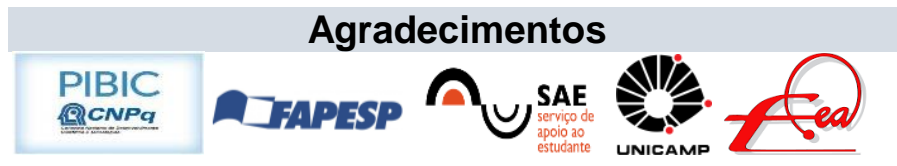

